\title{
The Influence of Teacher 's Teaching Leadership on the Effect of Classroom Teaching'
}

\author{
HuanLe Zhu, Jinfeng Li and Rongfu Wang \\ Nanchang institute of science \& technology,China
}

\begin{abstract}
Keywords: Teaching Leadership; Teaching Effect; Educational Philosophy
\end{abstract}
\begin{abstract}
The core of teacher's leadership is teacher's teaching leadership. Which is mainly reflected in the teacher's personality charm, classroom control and professional literacy, etc., these effects on classroom teaching have a direct and far-reaching impact. The student - centered teaching idea emphasizes the students' dominant position in the whole teaching process. How to achieve this goal effectively is a question that every teacher should think about. With the comprehensive promotion of quality education, the role of teacher's teaching leadership in improving the effect of classroom teaching has been paid more and more attention by educators, and has become the focus of educational research.
\end{abstract}

\section{Statement of Problem}

Preparatory stage for minority students is a special learning stage, matriculation stage of the results directly determine the pre-college students can choose their favorite professional and successfully closed down into the target institutions. At present, the status quo of classroom teaching students is worrying, even if the teacher hard to teach, students study hard, test scores are still not satisfactory, poor classroom teaching. The teaching effect is not obvious mainly in: the first teaching content can not advance with the times, the information society requires all aspects of the people have to advance with the times, keep falling behind. However, due to the same teaching materials and counseling materials, teachers teaching the use of teaching courseware, lesson plans, syllabus, also used before, resulting in obsolete teaching content, students can not meet the learning needs. The second main body of the reversed, the classroom teachers to eloquently explain and explain not only the lack of students a sense of self-existent, deprived students of the dominant position, but also resulting in student learning dependence, learning ability can not be improved. The ability of third matriculation students is quite different. For some students whose learning motivation is not strong and their ability of accepting is poor, the teachers lack effective teaching strategies and can not stimulate the students' inner learning interest.

Although many factors affect the effectiveness of classroom teaching, but the key lies in the teachers. Teachers need to "study the classroom", teachers of the classroom study is mainly reflected in: research students, research knowledge, research class relationships. [1] In short, to achieve student-centered classroom teaching, improve the effectiveness of classroom teaching, the core look at teachers, see the teaching leadership of teachers.

\section{The Role of Teacher's Teaching Leadership in Problem Solving}

The core of teacher's leadership is teacher's teaching leadership. The definition refers to a process that affects members of the community (including colleagues, students, parents, school administrators, etc.) in order to improve the quality of teaching and learning practice, the goal is to optimize the learning process of students, learning achievement and teaching effectiveness. [2] It is mainly reflected in the teacher's personality charm, classroom control and professionalism and so

\footnotetext{
${ }^{1}$ Project: Nanchang institute of science \& technology 2015 annual school - level teaching reform project "A Study on the Effectiveness of Teacher 's Leadership in Teaching Practice".( Item Number: NGJG-2015-21)
} 
on. The teaching leadership of teachers in the above-mentioned problems in the role of the main performance in the following points:

\section{Teachers' professional qualities affect the design of teaching content}

Teachers 'professional accomplishment is an important factor in the teaching leadership of teachers. Facing the different levels of pre-students, teachers should first understand the students' learning needs, and use Lev Vygotsky's theory of recent development area and their own professional knowledge and skills that as shown in Figure (a). Suitable for most students teaching content. At the same time, for most of the students' ability to accept and their existing level of knowledge, the use of reasonable teaching methods and teaching strategies, so as to provide good protection for the teaching effect.

\section{Recent Development Area}

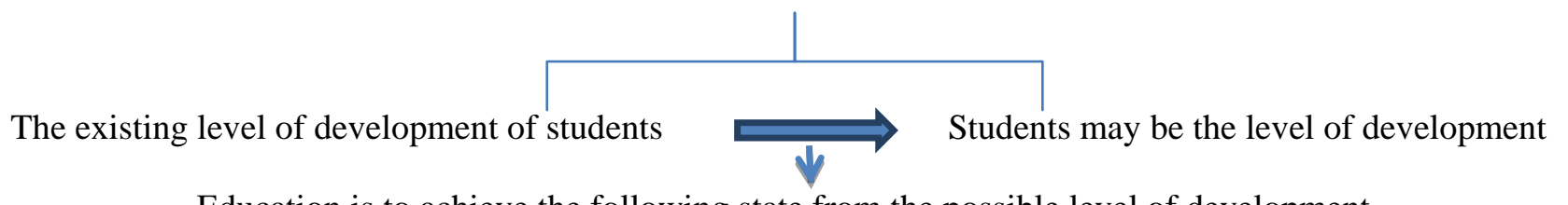

Education is to achieve the following state from the possible level of development

Figure a: Explanatory diagram of recent development[3]

\section{The classroom control ability of the teacher affects the student's dominant position}

Teachers' classroom control ability is an indicator of teachers' teaching leadership. Classroom teachers not only to control the rhythm of their class, classroom content output and the number of ways and means of output, but also to control the order of the classroom to control the direction of divergent thinking of students, so as to avoid the dominant position of students to highlight the limited Of teaching time is wasted on worthless problems, to ensure that the classroom atmosphere of students lively and orderly, so that each student in the discussion and learning to enhance their ability level.

\section{Teachers' personal charisma affects students' learning motivation}

Teachers' personal charisma mainly refers to teachers' personal conduct, sense of responsibility to work and love for students, which have a direct impact on students' interest in learning and motivation. Teachers are an example for students to learn and imitate. If teachers place a certain expectation on each student and help students to build self-confidence and encourage them to accomplish difficult goals, it will greatly improve students' learning motivation. According to the survey, most students said their degree of love of the course and learning efforts will be the impact of the personality of the substitute teachers.

\section{Ways to Improve the Teaching Leadership of Teachers}

Improving the teaching leadership of teachers is not a simple process. It is closely related to school organizational culture, teachers' self-development awareness and school management policies. Katzenmeyer and Moeller argue that schools with high levels of teacher leadership have seven characteristics on campus culture: 1. Focus on the development of continuing professional learning. 2. the leadership of teachers and skills recognition. 3.teacher autonomy and teaching and learning initiative. 4. collaboration between teaching and research staff. 5 . teachers involved in the leadership process. 6 . between teachers and managers to open communication. 7. an active campus atmosphere and professional attention to the environment. [4] These to improve the teaching leadership of teachers to provide some reference. 
First of all, teachers should pay attention to the organization of professional training and learning activities to improve the professionalism of teachers. Teacher's Day in 2014, Jinping Xi, general secretary of Beijing Normal University and the teachers and students of the forum had stressed that teachers in the 21st century should be "four have": ideals and beliefs, moral character, solid knowledge, there is love. Which is the core of a solid knowledge of teachers to have excellent professionalism. With the rapid development of the Internet and new information technology, teachers can not only participate in face-to-face academic meetings, but also apply online to participate in various national organizations, network training, the line can also communicate with experts through the instant communication. Teachers only real-time learning to charge, in order to better consolidate and update their professional knowledge, in order to practice in the teaching process capability. The teacher is the best state has always been that he or the students, never to remain an indefinite state of mind.

Followed by the establishment of "workshop" type of teacher leadership model. Teachers' workshops are aimed at supporting teachers' professional growth, providing a platform for them to exchange professional knowledge and meeting teachers' needs for professional development. Therefore, teachers' workshops can be influenced by grassroot teachers or novice teachers. Behavior of the organization. Teachers 'workshops are based on the principle of mutual help among teachers and give full play to teachers' initiative. Teachers share teaching strategies, skills and teaching models in a more systematic and systematic way. Teachers are provided with a professional forum for wisdom. Every teacher in the workshop has the opportunity to become a "leader". [5] "Teacher Workshop" activities design process that as shown in Figure (b).

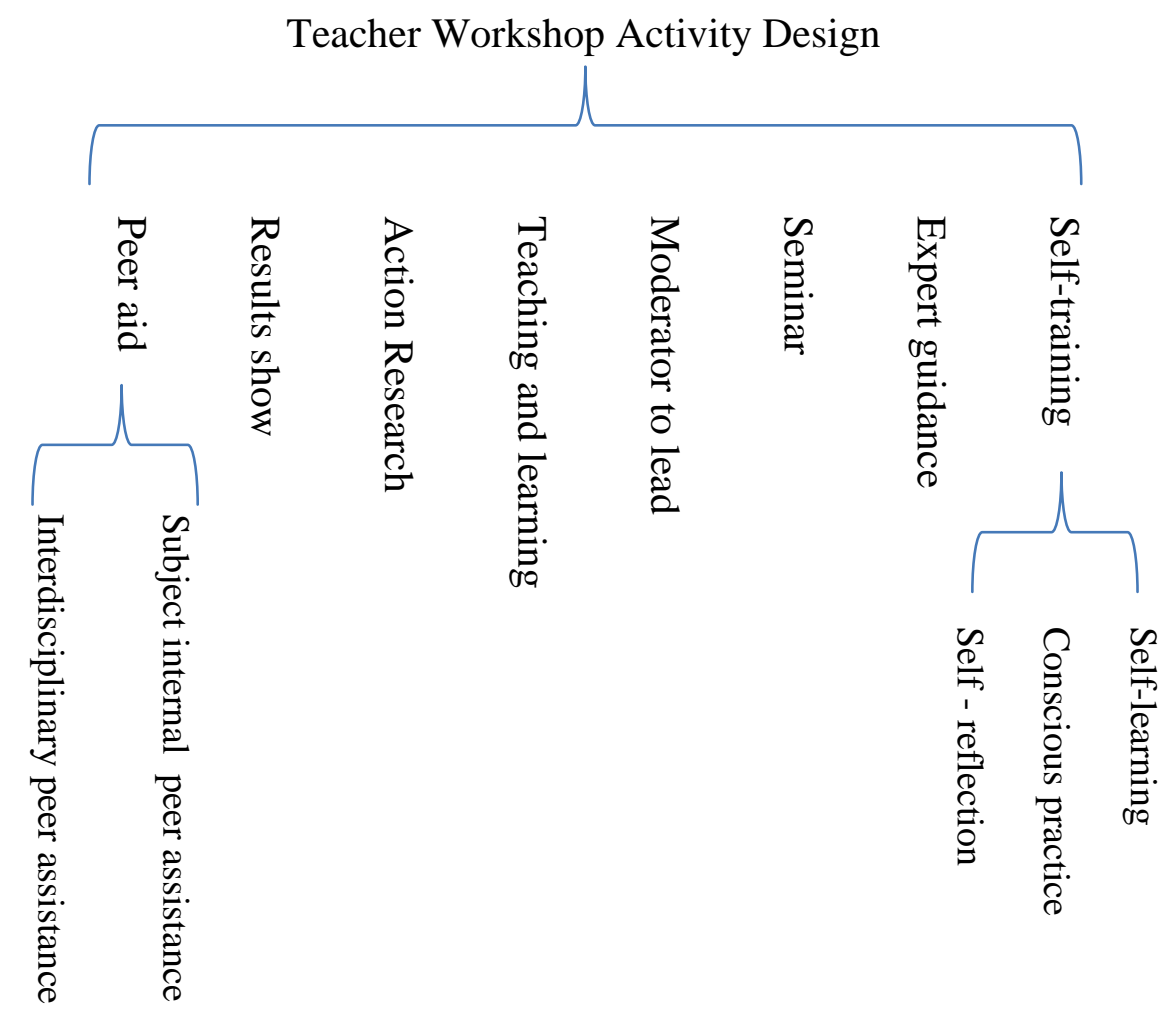

Figure b: Teacher Workshop Activity Design Flowchart

Once again it is important to organize various types of teaching competitions, and to enhance the skills of teachers of various levels. Teachers must have the ability to control the classroom, selfcultivation, classroom adaptability, teaching language arts, flexible use of teaching methods and the 
ability of a variety of teaching media must be improved, and these can be organized by the school teaching activities to observe the teacher class Activities to exercise. Of course, these abilities are not through the participation of one or two teaching competitions can be immediately increased, the need for teachers to learn and explore, and will learn the skills of internalization to their own classroom. Therefore, teachers must establish a "live to learn old" concept, will learn to improve themselves as part of life, so as to make their own classroom full of charm, teaching will have quality.

And then teachers should strive to cultivate the "three heart" that patience, love and care, and improve the teacher's personality charm. There are not two identical leaves in the world, let alone people. Teachers must face a variety of students, the students to solve the problem is more likely to be strange, in the face of these uncertain factors, the teacher must have a patience, to pay attention to ways and means to Rouke just to believe the stone to the stone . Love is the heart of love, love is the soul of education, education is the starting point of love, teachers shoulder the task of Lide tree, love has responsibility, love education, love students is the obligation of every teacher. Concerned about the students is equally important, teachers should not only care about students' learning, but also concerned about the lives of students, students with life difficult to give whatever help, teachers and teachers are also the best relationship between teachers and students.

Finally, teachers and teaching materials on the dialectical relationship between teachers should correctly grasp. The use of good materials, teachers is an "artist", the use of bad materials, teachers can only be a "teaching craftsman." Teaching materials is the basis for classroom teaching teachers to control the process of teaching the classroom must be ripe to grasp the teaching materials in the chapters of the logical relationship between the knowledge points, in addition, teachers should be good at the students and the actual situation Teaching needs, the content of teaching materials, structure, order and teaching methods and other aspects of appropriate adjustments and trade-offs, fully prepared for each classroom teaching content, be aware of, teachers should learn to use materials and make use of materials, so as to Become the master of teaching materials, and then to lead their own classroom teaching.

\section{Concluding remarks}

This paper mainly analyzes the problems existing in the classroom teaching of college preparatory courses and probes into the positive effects that teachers' teaching leadership can have on improving the teaching effect. At last, it puts forward several effective methods to improve the teaching leadership of teachers, With a view to the future of the relevant research help.

\section{References}

[1] Deshu Sun. Practice and Exploration of Teaching Reform of Advanced Mathematics in the Era of [J]. Science \& Technology, 2016-7-15.

[2] Yanlin Zheng,Luyi Li.MOOCTeacher 's Teaching Leadership: Connotation and Self promotion Strategy[J]. China audio-visual education, 2016(1),117-118.

[3] Qi Kong. On the Recent Development Area of Vygotsky[C]. Selected Achievements of Research Papers on Chinese Educational Theory and Practice,2016-6-1(11).

[4] Katzenmeyer, M. \& Moller, G. Awakening the sleeping gaint: Helping teachers develop as leaders [M].Thousand Oaks, CA: Corwin Press,Inc.2001: 79-84.

[5] Lifen Cai. A Research on The Problem and Countermeasure of Teacher Leadership in Teacher Professional Development[D]. Northeast Normal University, 2014.5(41). 